\title{
A COMPREHENSIVE GRID-BASED RAINFALL CHARACTERISTICS IN THE CENTRAL PLAIN RIVER BASIN OF THAILAND
}

\author{
Weerayuth PRATOOMCHAI ${ }^{1}$, Sarintip TANTANEE ${ }^{2}$ (D), Chaiwat EKKAWATPANIT ${ }^{3}$ (D)
}

DOI: $10.21163 /$ GT_2020.152.06

\begin{abstract}
:
Eight rainfall indicators were used to analyze the $5 \mathrm{~min} . \times 5 \mathrm{~min}$. grid-based rainfall characteristics in the central plain region of Thailand. The non-parametric statistics called Mann-Kendall test was applied to 32-year (1980-2011) time series data, statically significant (p-value $\leq 0.05$ ) and Kendall's tau correlation maps were considered for informative examination. Annual rainfall showed increasing trend in the upper basin and statically increasing by $35.8 \%$ of the whole basin. A number of rainy days (RD) and number of consecutive wet days (CWD) showed increasing by $70.2 \%$ and $57.9 \%$ of the basin for RD and CWD, respectively, while a number of consecutive dry days (CDD) exhibited decreasing trend over $85.0 \%$ of the study area even only $13.8 \%$ satisfied at $95 \%$ statically significant. The simple daily rainfall intensity (SDRI), heavy rainy days (HRD), max. 1-day, and max. 3-day demonstrated upward trends. The findings suggest that the region is shifting towards wetter condition. The explicit results of rainfall characteristics maps are expected to facilitate and allow various users to make better water resources management and overcome reluctant interpretation rainfall changes/trends for areas lacking of measured data as well as baseline information for climate change study.
\end{abstract}

Key-words: Chao Phraya River basin; Mann-Kendall test; rainfall indices; trend analysis.

\section{INTRODUCTION}

Rainfall is classified as a stochastic variable in both time and space. Over a last few decades, a number of evidences have been observed that rainfall characteristics are altering by the so called anthropogenic factor. For example, torrential rainfall or consecutive dry spell of rainy days is amplifying globally (Alexander et al, 2006 and IPCC, 2013).

Taking account for climate change inducing extreme rainfall events and disasters, many research articles point out that the global increases in the observed frequency and intensity of extreme rainfall events (e.g., Alexander et al., 2006; Donat et al., 2013; IPCC, 2013). For the global scale, the changes in precipitation extremes were spatially more complex since topography influence. However, on average, there was a trend towards wetter conditions for some precipitation indicators, for example, the intensity, frequency, and duration of extreme precipitation are increasing (Donat et al., 2013). For regional study, an article done by Herath et al. (2018) considering atmospheric temperature in Australia to quantify the properties of extreme rainfall events showing that the Clausius-Clapeyron relation was able to describe the extreme rainfall and daily maximum temperature. A study by Endo et al. (2009) showed that average precipitation intensity of wet days exhibited an increasing trend for many stations in the Southeast Asia. Manton et al. (2001) also pointed out that majority of the analyzed stations across the Southeast Asia showed upward trend in annual rainfall with significant decrease in the number of rainy days. Rainfall, especially an extreme event, has some links and influence on people's perception and their concerns (Pratoomchai et al, 2015).

\footnotetext{
${ }^{1}$ Department of Civil Engineering, Faculty of Engineering, King Mongkut's University of Technology North Bangkok, Bangkok, Thailand, weerayuth.p@eng.kmutnb.ac.th

${ }^{2}$ Department of Civil Engineering, Faculty of Engineering, Naresuan University, Phitsanulok, Thailand, sarintipt@nu.ac.th

${ }^{3}$ Department of Civil Engineering, Faculty of Engineering, King Mongkut's University of Technology Thonburi, Bangkok, Thailand, chaiwat.ekk@kmutt.ac.th
} 
The latest report, Global Risks Reports, by the World Economic Forum (2018) points out that extreme weather events, natural disasters, and failure of climate change mitigation and adaptation are three out of the top five global risks in terms of livelihood and influence on global economic growth.

In Thailand, a few studies have been done on rainfall and temperature extreme indicators, but those results were classified as station-based studies (Limjirakan et al, 2010; Limsakul et al, 2010; Limsakul and Singhruck, 2016). An assessment will be more useful and applicable if high station density was used and transformed a analyzed result to a map (King et al, 2013). To fulfil this knowledge gap, this paper was carried out in order to analyze and construct the spatial distribution of rainfall patterns and trends in the Chao Phraya River basin.

\section{STUDY AREA}

Chao Phraya River basin (CPRB) is located in the central plain region of Thailand as shown in Fig. 1 (a). It covers for $157,284 \mathrm{~km}^{2}$. This area is home for approximately 34 million people or $51.7 \%$ of the country population and that shared for $73 \%$ of the overall country GDP because it includes Bangkok, the capital city. The region can separate into upper basin which consists of the Ping, Wang, Yom, and Nan Rivers and lower part has three tributaries, i.e., the Sakaekrang, Pasak, and Chao Phraya Rivers. Flooding is a major dilemma problem in this area (GISTDA, 2018; Nusit et al, 2019). Based on satellite imaged data which were analyzed by the Geo-Informatics and Space Technology Development Agency or GISTDA (2018), approximately 1,500-25,560 $\mathrm{km}^{2}$ of the CPRB were classified as annual flood inundations over the period 2005 to 2016. Major driving factor associates to this problem is torrential rainfall that will predominate the basin during May to October (rainy season). In addition, rainfall in this region varies greatly by season as a result of complex interaction among the climate circulation in the Indo-Pacific region together with orographic conditions (e.g., Misra and DiNapoli, 2014; Takahashi and Yusunari, 2006).

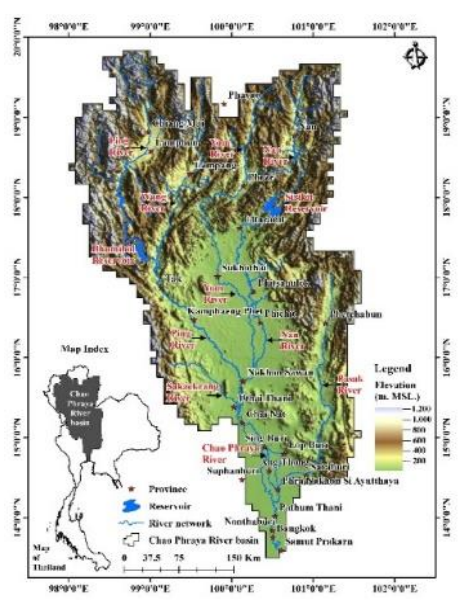

(a)

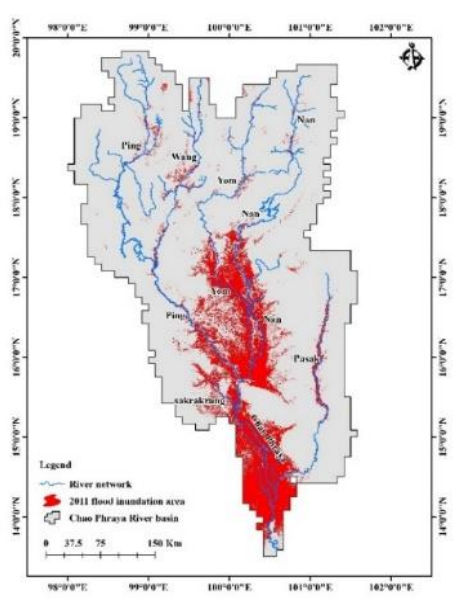

(b)

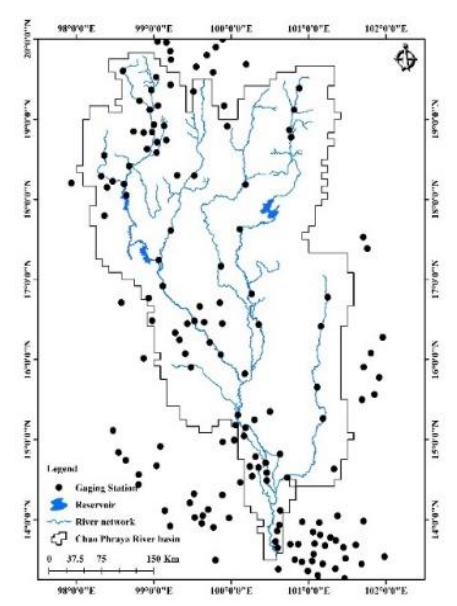

(c)

Fig. 1 Chao Phraya River basin in Thailand: (a) upper part of the basin is mountainous range while the central and lower parts are flood plain areas, (b) 2011-flood inundation area, and (c) IMPAC-T gaging stations used.

The CPRB is also considered as a climate change hotspot of Thailand. 2011 flood event was recorded as the extremely historical flood disaster. As shown in the shading area of Fig. 1 (b), the lower Yom and Nan Rivers and lower part of the basin including northern parts of Bangkok were flooded for almost 2 to 4 months. Thus, this region has been selected as the study area to improve understanding of spatial distribution of rainfall characteristics. 


\section{METHODOLOGY}

A non-parametric test called Mann-Kendall test, which is a practical and famous tool for examining whether statically significant trend of hydro-meteorological time-series data (Helsel and Hirch, 2002; Haidu and Magyari-Sáska, 2009; Pravalie, 2014), was applied for this study.

Kendall's tau $(\tau)$ correlation is an index to measures the strength of the monotonic relationship (directions) in time-series data (Kendall, 1975). Tau is a rank-based procedure and is therefore resistant to the effect of a small number of unusual values. It is well-suited for variables which exhibit skewness, e.g., rainfall, around the general relationship. The strength of the evidence whether statistically significant exist is presented by p-value. Typically, in hydro-climatology trend test, if pvalue $\leq 0.05$ or at $95 \%$ confidence level it is presumed that statistically significant exist in the examination data.

In this study, the Kendall Family of Trend Tests (Helsel et al, 2006), the Fortran source code, which was developed by the U.S. Geological Survey, was modified to the grid-based rainfall. To figure out grid-based rainfall characteristics in the CPRB, eight indicators as listed in Table 1 were examined. Mostly, they are based on the recommendation by World Meteorological OrganizationCommission for Climatology (WMO-CCI)/World Climate Research Program (WCRP)/Climate Variability and Predictability (CLIVAR) project's Expert Team on Climate Change Detection Indices (ETCCDI) (Zhang et al, 2011).

Table 1.

Rainfall indicators used in the study.

\begin{tabular}{cllc}
\hline No & \multicolumn{1}{c}{ Indicator name } & \multicolumn{1}{c}{ Definition } & Unit \\
\hline 1 & Annual rainfall & Annual total rainfall & $\mathrm{mm}$ \\
2 & Number of rainy days & Annual count of days when rainfall $\geq 1 \mathrm{~mm}$ & Days \\
3 & Number of consecutive wet days & Annual maximum number of consecutive days with rainfall $\geq 1 \mathrm{~mm}$ & Days \\
4 & Number of consecutive dry days & Annual maximum number of consecutive days with rainfall $<1 \mathrm{~mm}$ & Days \\
5 & Simple daily rainfall intensity & Annual total rainfall divided by number of rainy days & $\mathrm{mm} \mathrm{day}^{-1}$ \\
6 & Number of heavy rainy days & Annual count of days when rainfall $\geq 20 \mathrm{~mm}$ & Days \\
7 & Max. 1-day rainfall & Annual maximum 1-day rainfall & $\mathrm{mm}$ \\
8 & Max. 3-day rainfall & Annual maximum consecutive 3-day rainfall & $\mathrm{mm}$ \\
\hline
\end{tabular}

\section{FORCING DATASET}

This study we used the $5 \mathrm{~min} . \times 5 \mathrm{~min}$. (approximately $9.3 \mathrm{~km} . \times 9.3 \mathrm{~km}$.) grid-based data that was an outcome of the Integrated study on Hydro-Meteorological Prediction and Adaptation to Climate Change in Thailand (IMPAC-T Project). Several achievements of the project were published on the Hydrological Research Letters (Special Collection 2) which is available on http://www.hrljournal.org/special-collections/special-collection-2. There are two datasets called K10 and T12 under the project archive (Kotsuki et al., 2014). Both of them are $5 \mathrm{~min} . \times 5 \mathrm{~min}$. horizontal resolution which were created from measured gaging stations (Fig. 1 (c)). The K10 comprises of 7 climate dataset, i.e., rainfall, surface temperature, wind speed, specific humidity, long-wave and shortwave radiations, and atmospheric pressure while the T12 is only rainfall data. However, T12 is covered a 32-year historical data from 1980 to 2011 whereas the K10 is extended in 1981-2004 (24 years). Therefore, T12 data was used for this study since the main objective was only focused on rainfall. 


\section{RESULTS AND DISCUSSION}

The entire area of the region was divided by grid size of $5 \mathrm{~min} . \times 5 \mathrm{~min}$. horizontal resolution into 1,925 grids in total. A simple percentage was used to show a quantitative examination or general trend of the study. Three types of spatial distribution maps, i.e., 32-year average value, Kendall's tau correlation, and p-value, were created for all indicators. Results and discussion were made as follows:

\subsection{Annual Rainfall}

Generally, average annual rainfall in the area over the period 1981-2011 (32 years) was varied between 871-1,608 $\mathrm{mm}$ (1,169 $\mathrm{mm}$ using area-averaged over the entire basin) as shown in Fig. 2 (a). It was clearly seen that areas along the Yom and Nan Rivers were received more rainfall $(1,200-1,400$ $\mathrm{mm}$ ) if compared to other tributary areas. Based on the isohyetal rainfall, approximately 1,000-1,100 $\mathrm{mm}$ were found over the Ping and Wang sub-basins except the upper Ping River that received higher amount of 1,300-1,500 mm. Meanwhile, the lower part of the CPRB except Bangkok and her vicinity areas was gained precipitated water approximately $900 \mathrm{~mm}$, on average. For the capital city and surrounding regions, which are located by the Gulf of Thailand, were subjected to rain water of 1,200$1,400 \mathrm{~mm}$.

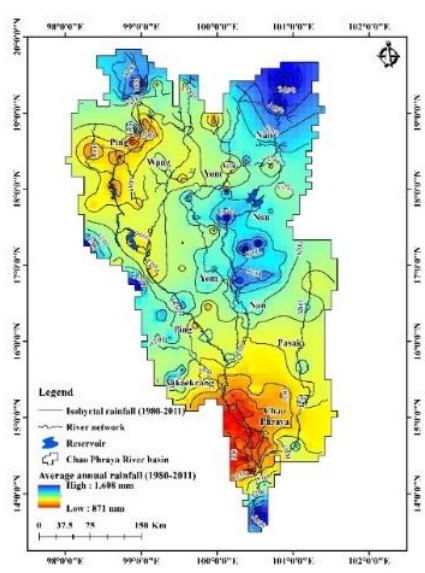

(a)

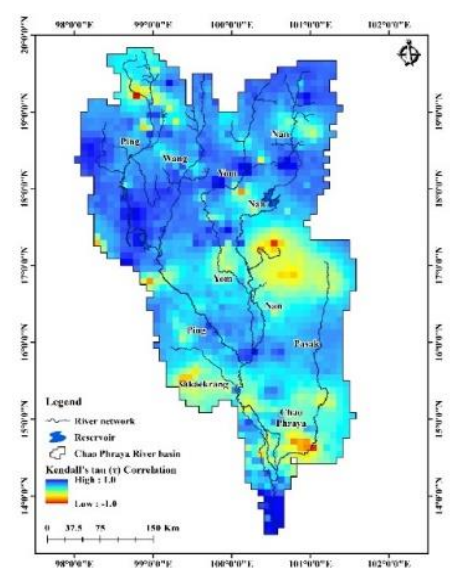

(b)

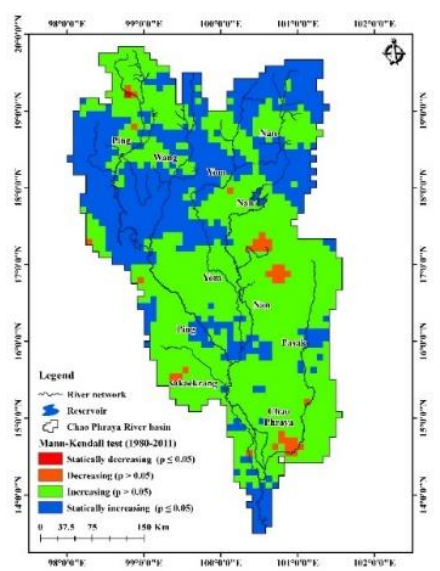

(c)

Fig. 2 Spatial distribution of the average annual rainfall (a), Kendall's tau (b), and Mann-Kendall statically test (c).

Based on the area-averaged, rainy season rainfall was 1,020 mm (ranged between 761-1,378 $\mathrm{mm}$ on average) which was considered for $87.2 \%$ of the average annual rainfall. Based on the findings, it was noteworthy that 1,858 grids ( $96.5 \%$ of the whole basin) showed increasing trend.

Fig. 2 (b and c) show the examination of spatial distribution of Kendall's tau and statistically significant test ( $\mathrm{p}$-value). The findings indicated that annual and rainy season rainfall generally showed in upward trend. And they were strongly increasing in the upper areas of the basin. 35.8\% and $38.0 \%$ of the basin areas were statically increasing in annual and rainy season, respectively. However, there was a few percentage of the total area subjected to decreasing trend. Another point to note on this finding is the areas long the Ping and Wang Rivers normally receiving less rainfall are being got more annual rainfall progressively and statically. Using the area-averaged, a general trend of annual rainfall linear regression was increase by $6.8 \mathrm{~mm}_{\text {year }}^{-1}$ or $68 \mathrm{~mm}$ decade ${ }^{-1}$. The quantitative figures from our analysis could provide detail information at regional assessment. 


\subsection{Number of Rainy Days}

A number of rainy days $(\mathrm{RD})$ are a day that measured rainfall $\geq 1 \mathrm{~mm}$. In the study area, there were approximately 71-190 days, on average, in RD distributed over the basin annually. More wet days in mountainous region and relatively low in the low-lying areas along the rivers especially in the Chao Phraya River plain (Fig. 3 (a)). Based on the Kendall's tau and p-value (Fig. 3 (b and c)), 1,352 grids $(70.2 \%$ of the total area) showed increasing trend and 543 grids out of the RD increasing grids were statically significant. Whereas about $29.8 \%$ of the basin showed decreasing in RD and statically significant by with 89 grids or only $4.6 \%$ of the whole CPRB.

Overall, RD tended to increase by 0.44 -day year ${ }^{-1}$ with the fluctuation between +4.54 (increasing) and - 2.50-day year ${ }^{-1}$ (decreasing). This finding is not agreed with Limsakul and Singhruck (2016) that found a general trend in decreasing of RD by 0.99-day decade ${ }^{-1}$. Although there is mixed spatial distribution pattern (upward or downward) on RD; however, it can be noted that an area on the left by the middle Nan River is relatively wetter region than the others. In contrast, over the upper-end of the Nan River the RD showed declining trend with statically significant and was agree with Manton (2001).

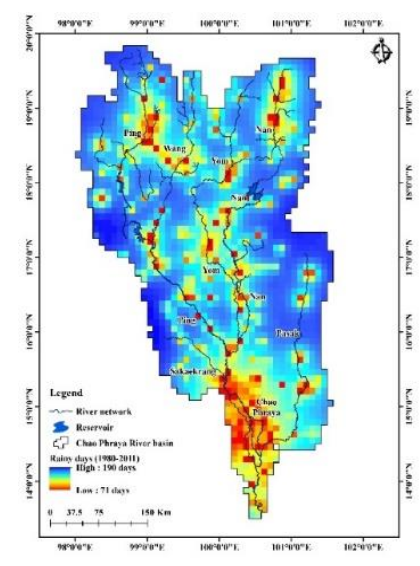

(a)

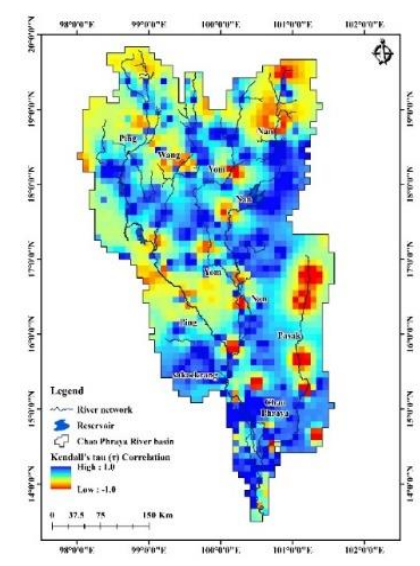

(b)

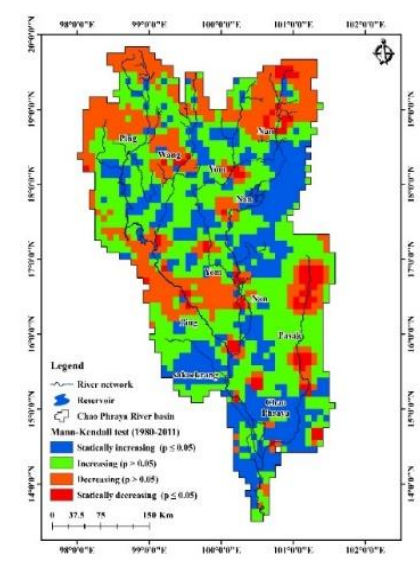

(c)

Fig. 3 Spatial distribution of the average number of rainy days (a), Kendall's tau (b), and Mann-Kendall statically test (c).

\subsection{Number of Consecutive Wet Days}

The average of Number of Consecutive Wet Days (CWD) was varied between 7 to 64 days over the study period. It is quite scatter spatial distribution from place to place. Relatively low CWD in low land areas that lie along river valleys particularly by the Chao Phraya River plain, whereas the watershed divide which is a mountainous range, CWD are relatively high. The spatial distribution of Kendall's tau correlation of CWD revealing that the low land areas lie along the rivers are subjected to increase in CWD. In addition, the regions that corresponding to positive Kendall's tau (increasing in the CWD in the time series) with statically significant were about 418 grids or $21.7 \%$ of the basin. On the other hand, the upper areas in the Pasak, Nan, Yom, Wang, and Ping Rivers were corresponding to decreasing trend in CWD. Overall, 811 (126) grids or $42.7 \%$ (6.5\%) of the CPRB show negative trend (statically significant) in CWD. The rate of change of the trend analysis showed that CWD ranged +1.49 (increasing) to -1.22-day year-1 (decreasing) with the basin-wide averaged of 0.08 -day year $^{-1}$. This grid-based examination of CWD in the study show a contrast finding by Limsakul and Singhruck (2016) that show a 0.027-day year-1 (based on 41 stations) downward trend in CWD across Thailand. 


\subsection{Number of Consecutive Dry Days}

Consecutive dry days (CDD), was also included in the study. Basically, the consecutive no rainfall days or dry days (rainfall $<1 \mathrm{~mm}$ ) were ranged 40-84 days (almost 3 months for the maximum) distributed over the entire basin. The longest prevailing dry areas were located in the upper parts of the Ping, Wang, and Yom Rivers.

On the other hand, The Nan, lower Ping and Yom, and lower CPRB areas were relatively short duration in CDD. However, the areas subjected to long duration in CDD were reducing. This signal was interpreted from Kendall's tau and p-value. Overall, the linear regression of CDD was descending by -0.33-day year ${ }^{-1}$. In the big picture, it was clearly to note that CDD was trending to decrease. 1,635 grids or approximately $85.0 \%$ of the total basin area showed CDD decreasing although only 267 grids were satisfied with $95 \%$ confidence level.

\subsection{Simple Daily Rainfall Intensity}

Simple daily rainfall intensity (SDRI) is the total annual rainfall divided by the annual number of rainy days. In general, the analysis revealed that SDRI was approximately 6 to $18 \mathrm{~mm} \mathrm{day}^{-1}$. Furthermore, the intensity which was less than $10 \mathrm{~mm} \mathrm{day}^{-1}$ were accounted for 1,838 grids $(95.5 \%$ of the CPRB) as illustrated in Fig. 4 (a). Considering of the general trend of annual rainfall, RD, and SDRI altogether implied that the basin tends to wetter condition but rainfall intensity less than a 10 mm day ${ }^{-1}$ was predominating in the basin. The Kendall's tau and statically test are showed in Fig. 4 (b) and Fig. 4 (c) indicating that SDRI exhibited increasing trend. About 77.5\% (1,493 grids) of the basin were increasing trend and 628 grids out of 1,493 grids increasing with $95 \%$ confidence level. However, there were some regions, especially in the Lower CPRB (floodplain area), showed decreasing in SDRI. Approximately 157 grids from the entire basin were categorized in statically significant deceasing.

Based on the trend analysis, overall signal of SDRI was slightly increasing by $0.02 \mathrm{~mm}$ day $^{-1}$ year ${ }^{-1}$ over the study period. The rate of change of the SDRI from our result is relatively closed to the previous study $\left(0.17 \mathrm{~mm} \mathrm{day}^{-1}\right.$ decade $\left.^{-1}\right)$ by Limsakul and Singhruck (2016). In fact, there is no monotonic SDRI trend in the complex topography and large basin, our analysis showed that the fluctuation of SDRI across the CPRB were +0.33 and $-0.70-\mathrm{mm} \mathrm{day}^{-1}$ year $^{-1}$ for the maximum and minimum of SDRI, respectively. For example, the observations of mountainous rainfall in the upper Ping River are increasing with significant signal (Kuraji et al, 2009).

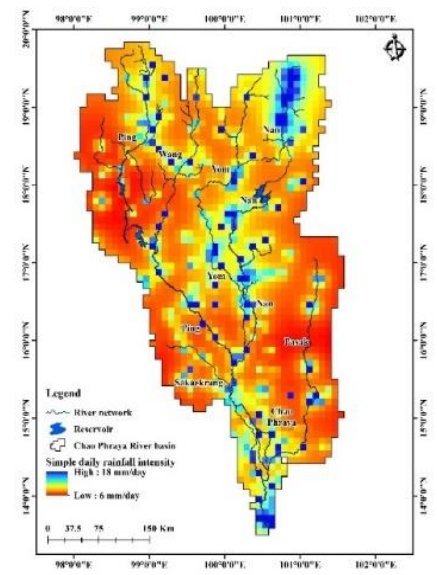

(a)

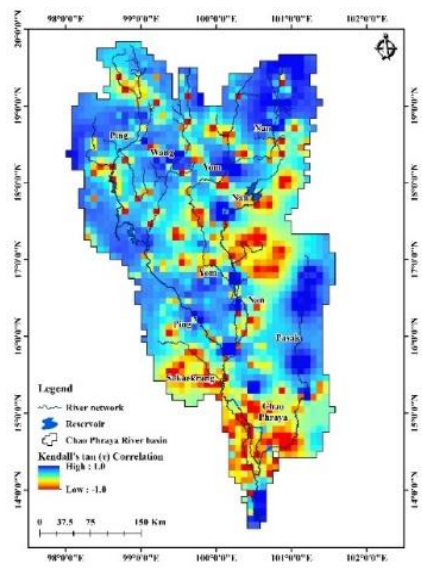

(b)

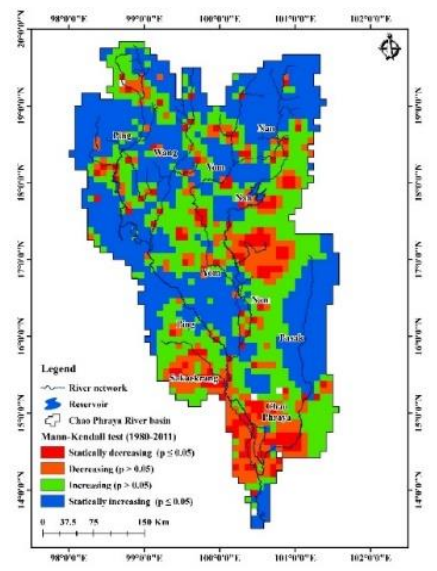

(c)

Fig. 4 Spatial distribution of the simple daily rainfall intensity (a), Kendall's tau (b), and Mann-Kendall statically test (c). 


\subsection{Number of Heavy Rainy Days}

A day that receives rainfall greater or equal $20 \mathrm{~mm}$ is classified as a heavy rainy day (HRD). In the study area, HRD exhibited between 4 to 26 days and relatively high in the upper Nan River. In general, a number of HRD over the study period were increased by 1,554 grids $(80.7 \%$ of the study area) with $36.3 \%$ (699 grids) of the CPRB showed statically significant increasing. However, there were some areas subjected to decrease in HRD and only a few percentage (4\% of the basin) showed statically significant decreasing. HRD is one factor relating to a degree of rainfall inducing natural disaster. The regression analysis showed that HRD was increasing by 0.11 day year $^{-1}$, on average, with the fluctuation range of \pm 0.67 day year ${ }^{-1}$. Based on the findings, Upper Nan River sub-basin is the region that likely to be risky because there tends to increasing in rainfall amount, SDRI, and HRD while decreasing in RD, CWD and CDD. Combination of the mentioned factors imply that the area might face with extreme rainfall.

\subsection{Maximum 1-Day and 3-Day Rainfall}

Fig. 5 and Fig. 6 show the spatial distribution of maximum 1-day and 3-day rainfall, respectively. The Kendall's tau and classification of p-value are also presented. 32-year average of 3day rainfall ranged between $66-230 \mathrm{~mm}$.

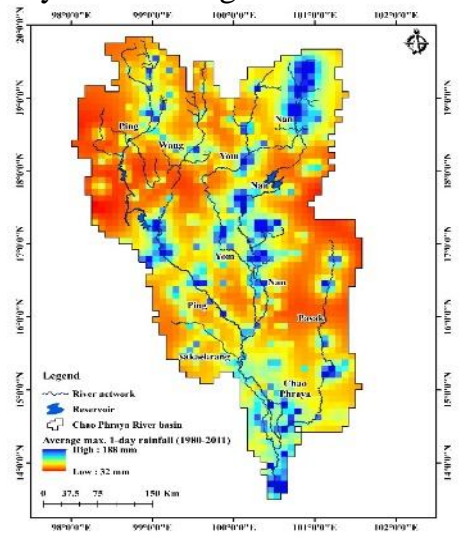

(a)

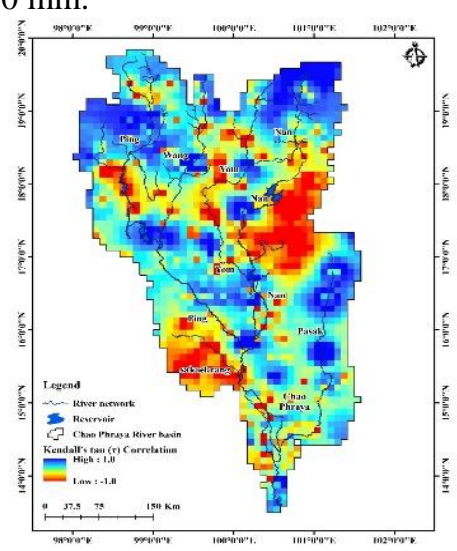

(b)

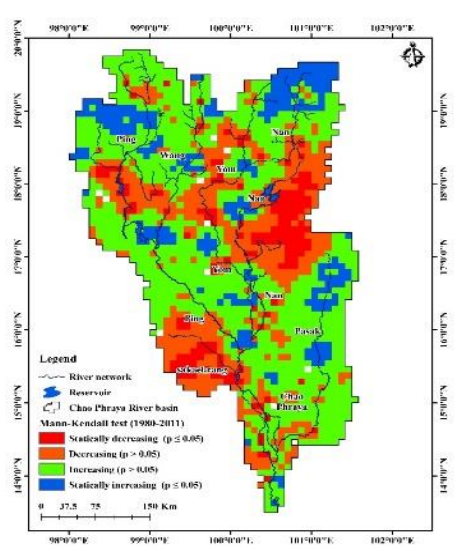

(c)

Fig. 5 Spatial distribution of the maximum 1-day rainfall (a), Kendall's tau (b), and Mann-Kendall statically test (c).

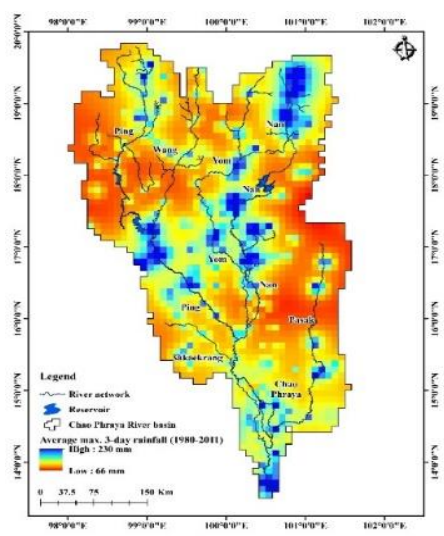

(a)

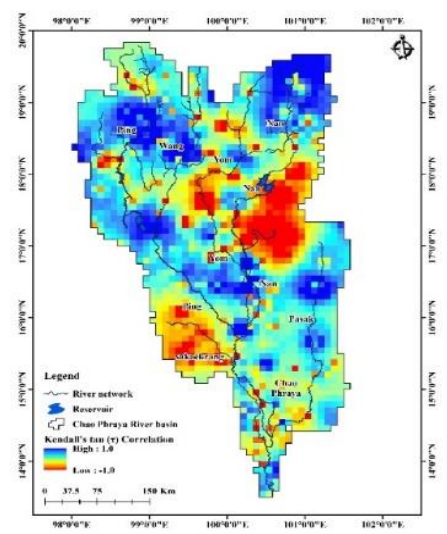

(b)

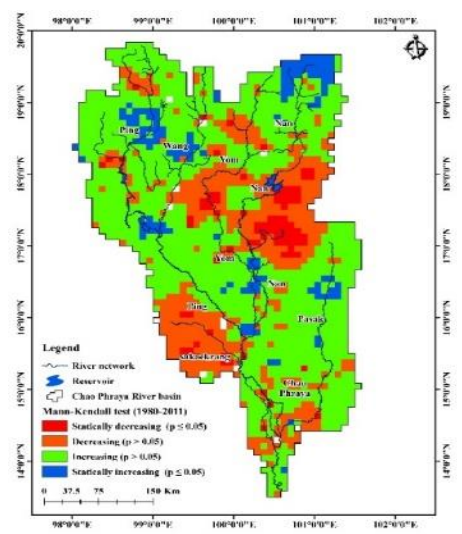

(c)

Fig. 6 Spatial distribution of the maximum 3-day rainfall (a), Kendall's tau (b), and Mann-Kendall statically test (c). 
It was clear from the figures that grids locations near by rivers, particularly upper Nan River, showed more pronounced value of maximum rainfall. Majority of the whole basin subjected to an increase of both max. 1-day and max. 3-day. These were interpreted from positive sign of the Kendall's tau maps. Approximately 1,240 grids ( $64.4 \%$ of the basin) and 1,331 grids (or $69.1 \%$ of the basin) were exhibited of increasing max. 1-day and max. 3-day, respectively. If considered in terms of statically increasing or decreasing, there were not much different in the directions. 248 (174) and 134 (91) grids or $12.8 \%(9.0 \%)$ and $7.0 \%(4.7 \%)$ of the entire basin satisfied with $95 \%$ confidence level of increasing (decreasing) for the max. 1-day and max. 3-day, respectively.

\section{CONCLUSIONS}

This study focuses on spatial distribution and trends of rainfall characteristics using daily gridbased rainfall. The Mann-Kendall test was used to identify the CPRB's rainfall characteristics for eight indicators as summarized in Table 2. The table shows percentage of the areas that subjected to increase/decrease for two categories, increasing (overall trend) and statically increasing (satisfy at 95\% confidence level). In short, the basin trends towards wetter condition especially over the upper sub-basins (the Ping, Wang, and Nan sub-basins). 97.9\% (35.8\%) of the CPRB were subjected to the increase (statically significant) of annual rainfall with the rate of $6.8 \mathrm{~mm}_{\text {year }}{ }^{-1}$. Increasing of the RD and CWD and decreasing of CDD for $70.2 \%, 57.3 \%$, and $84.9 \%$, respectively, pointed out the likelihood wetter condition in this region. For the SDRI, max. 1-day, and max. 3-day indicators showed upward trend and also predominated majority areas of the basin.

We would note that this was the first time for grid-based examination on rainfall characteristics over the most important area in Thailand. Various spatial distribution maps for the 32-year average and statically test provide the base values, probabilistic trends, and practical information towards rainfall monitoring as well as the baseline data for climate change study. This local assessment will provide a clearer perspective of rainfall characteristics and beneficial to various users as well as a decision-making stage associated with water resources engineering and disaster mitigation in the study area.

Table 2 .

Summary of the rainfall characteristics in the study area.

\begin{tabular}{|c|c|c|c|c|c|c|c|}
\hline \multirow{3}{*}{ Rainfall indicators } & \multicolumn{4}{|c|}{ Trends ( $\%$ of the basin area) } & \multicolumn{3}{|c|}{ Trends/Changes year ${ }^{-1}$} \\
\hline & \multicolumn{2}{|c|}{ Increasing } & \multicolumn{2}{|c|}{ Decreasing } & \multirow[b]{2}{*}{ Max. } & \multirow[b]{2}{*}{ Min. } & \multirow{2}{*}{$\begin{array}{c}\text { Area } \\
\text { averaged }\end{array}$} \\
\hline & Overall & $\begin{array}{l}\text { Statically } \\
\text { significant }\end{array}$ & Overall & $\begin{array}{l}\text { Statically } \\
\text { significant }\end{array}$ & & & \\
\hline Annual rainfall (mm) & 97.9 & 35.8 & 2.1 & $\mathrm{n} / \mathrm{a}$ & 21.6 & -9.22 & 6.8 \\
\hline Number of rainy rays (Days) & 70.2 & 28.2 & 29.8 & 4.6 & 4.54 & -2.50 & 0.44 \\
\hline Number of consecutive wet days (Days) & 57.3 & 35.6 & 42.7 & 6.5 & 1.49 & -1.22 & 0.08 \\
\hline Number of consecutive dry days (Days) & 15.1 & $\mathrm{n} / \mathrm{a}$ & 84.9 & 13.8 & 0.55 & -1.92 & -0.33 \\
\hline Simple daily rainfall intensity $\left(\mathrm{mm} \mathrm{day}^{-1}\right)$ & 77.5 & 44.9 & 22.5 & 8.1 & 0.33 & -0.70 & 0.02 \\
\hline Number of heavy rainy days (Days) & 80.7 & 36.3 & 19.3 & 4 & 0.67 & -0.67 & 0.11 \\
\hline Max. 1-day rainfall (mm) & 64.4 & 12.8 & 35.6 & 9 & 1.66 & -2.97 & 0.08 \\
\hline Max. 3-day rainfall (mm) & 69.1 & 6.9 & 30.9 & 4.7 & 2.17 & -3.18 & 0.18 \\
\hline
\end{tabular}




\section{Acknowledgements}

This research was supported by "Advancing Co-design of Integrated Strategies with Adaptation to Climate Change in Thailand (ADAP-T)" (Grant Number: JPMJSA1502) supported by the Science and Technology Research Partnership for Sustainable Development (SATREPS), JST-JICA and the funding provided by the Department of Civil Engineering, King Mongkut's University of Technology Thonburi, under grant number CE-KMUTT-5802.

\section{R E F E R E N C E S}

Alexander, L.V., Zhang, X., Peterson, T.C., Caesar, J., Gleason, B., Klein Tank, A.M.G., Haylock, M., Collins, D., Trewin, B., Rahimzadeh, F., Tagipour, A., Rupa Kumar, K., Revadekar, J., Griffiths, G., Vincent, L., Stephenson, D.B., Burn, J., Aguilar, E., Brunet, M., Taylor, M., New, M., Zhai, P., Rusticucci, M., VazquezAguirre, J.L. (2006) Global observed changes in daily climate extremes of temperature and precipitation. $J$. Geophys. Res., 111, D05109

Donat, M.G., Alexander, L.V., Yang, H., Durre, I., Vose, R., Dunn, R.J.H., Willett, K.M., Aguilar, E., Brunet, M., Caesar, J., Hewitson, B., Jack, C., Klein Tank, A.M.G., Kruger, A.C., Marengo, J., Peterson, T.C., Renom, M., Oria Rojas, C., Rusticucci, M., Salinger, J., Elrayah, A.S., Sekele, S.S., Srivastava, A.K., Trewin, B., Villarroel, C., Vincent, L.A., Zhai, P., Zhang, X., Kitching, S. (2013) Updated analyses of temperature and precipitation extreme indices since the beginning of the twentieth century: the HadEX2 dataset. J. Geophys. Res., 118, 2098-2118

Endo, N., Matsumoto, J., Lwin, T. (2009) Trends in precipitation extremes over Southeast Asia. SOLA, 5, 168171 doi: http://dx.doi.org/10.2151/sola.2009-043.

GISTDA, (2018) Thailand Flood Monitoring System, Geo-Informatics and Space Technology Development Agency (Available online http://flood.gistda.or.th/ (accessed 1 March 2018)).

Haidu, I., Magyari-Sáska Zs., (2009) Animated Sequential Trend Signal Detection in Finite Samples. Information Technology Interfaces, IEEE Publication, Catalog Number CFP 09498-PRT, pp.249-254. ISSN 1330-1012., DOI 10.1109/ITI.2009.5196088

Helsel, D.R., Hirsch, R.M. (2002) Statistical methods in water resources: U.S. Geological Survey Techniques of Water-Resources Investigations. $524 \mathrm{pp}$.

Helsel, D.R., Mueller, D.K., Slack, J.R. (2006) Computer program for the Kendall family of trend tests: U.S. Geological Survey Scientific Investigations Report 2005-5275, 4 p.

Herath, S.M., Sarukkalige, R., Nguyen, V.T. (2018) Evaluation of empirical relationships between extreme rainfall and daily maximum temperature in Australia. J. Hydrol., 556, 1171-1181

IPCC. (2013) Climate Change 2013: The Physical Science Basis. Contribution of Working Group I to the Fifth Assessment Report of the Intergovernmental Panel on Climate Change. IPCC: Cambridge, UK.

Kendall, M. G. (1975) Rank Correlation Methods 4th ed, Charles Griff, London.

King, A.D., Alexander, L.V., Donat, M.G. (2013) The efficacy of using gridded data to examine extreme rainfall characteristics: a case study for Australia. Int. J. Climatol., 33, 2376-2387.

Kotsuki, S., Tanaka, K., Watanabe, S. (2014) Projected hydrological changes and their consistency under future climate change in the Chao Phraya River basin using multi-model and multi-scenario of CMIP5 dataset. Hydrolo. Res. Lett., 8, 27-32.

Kuraji, K., Mei, G., Kowit, P. (2009) Inter-annual and spatial variation of altitudinal increase in rainfall over Mount Inthanon and Mae Chaem watershed, Northern Thailand. Hydrolo. Res. Lett., 3, 18-21.

Limjirakan, S., Limsakul, A., Sriburi, T. (2010) Trends in temperature and rainfall extremes in Bangkok Metropolitan area. J. Environ. Res., 32, 31-48.

Limsakul, A., Limjirakan, S., Sriburi, T. (2010) Observed changes in daily rainfall extremes along Thailand's coastal zone. J. Environ. Res., 32, 49-68.

Limsakul, A., Singhruck, P. (2016) Long-term trends and variability of total and extreme precipitation in Thailand. Atmospheric Res., 169, 301-317 
Manton, M.J., Della-Marta, P.M., Haylock, M.R., Hennessy, K.J., Nicholls, N., Chambers, L.E., Collins, D.A., Daw, G., Finet, A., Gunawan, D., Inape, K., Isobe, H., Kestin, T.S., Lefale, P., Leyu, C.H., Lwin, T., Maitrepierre, L., Ouprasitwong, N., Page, C.M., Pahalad, J,, Plummer, N., Salinger, M.J., Suppiah, R., Tran, V.L., Trewin, B., Tibig, I., Yee, D. (2001) Trends in extreme daily rainfall and temperature in Southeast Asia and the South Pacific: 1961-1998. Int. J. Climatol. 21: 269-284

Misra, V., DiNapoli, S. (2014) The variability of the Southeast Asian summer monsoon. Int. J. Climatol. 34, 893-901

Nusit, K., Tantanee, S., Subsomboon, K., Leungvichcharoen, S., Yiemwattana, S. (2019) The design of flood protection along Nan River, Phitsanulok province, Thailand. Geographia Technica, 14, Special Issue 2019, pp. 129-137

Pravalie, R. (2014) Analysis of temperature, precipitation and potential evapotranspiration trends in southern Ol tenia in the context of climate change. Geographia Technica, 9(2), 68-84

Pratoomchai, W., Kazama, S., Manandhar, S., Ekkawatpanit, C., Saphaokham, S., Komori, D., Tongduang, J. (2015) Sharing of people's perceptions of past and future hydro-meteorological changes in the groundwater use area. Water Resour Manage. 29: 3807-3821

Takahashi, H.G., Yasunari, T. (2006) Climatological monsoon break in rainfall over Indochina singularity in the seasonal march of the Asian summer monsoon. J. Clim. 19, 1545-1556.

Yue, S., Pilon, P., Cavadias, G. (2002) Power of the Mann-Kendall and Spearman's rho tests for detecting monotonic trends in hydrological series. J. Hydrol, 254-271

The World Bank. (2012) Thai Flood 2011: Rapid Assessment for resilient recovery and reconstruction planning. https://www.gfdrr.org/thaifloods2012.

World Economic Forum. (2018) The global risks report 2018, 13th ed. 80 pp (Available on http://wef.ch/risks2018).

Zhang, X., Alexander, L.V., Hegerl, G.C., Klein-Tank, A., Peterson, T.C., Trewin, B., Zwiers, F.W. (2011) Indices for monitoring changes in extremes based on daily temperature and precipitation data. WIREs Clim Change 2: 851-870 